\title{
Fatores determinantes da remuneração financeira dos contadores
}

\section{Determinant factors of accountants' financial remuneration}

\author{
Samuel Lyncon Leandro de Lima ${ }^{1}$, Adriano Cavalcante da Silva ${ }^{2}$, \\ Maria da Piedade Araújo ${ }^{3}$
}

\section{Resumo}

O propósito dessa pesquisa foi analisar por meio de uma abordagem econométrica os fatores determinantes dos salários de contadores dos municípios de Cascavel, Foz do Iguaçu e Toledo no ano de 2015. Para desenvolvimento da pesquisa empregou-se o levantamento documental dos dados na base da Relação Anual de Informações Sociais. Para organização e análise dos dados foram empregados os procedimentos metodológicos quantitativos. Além disso, com base na literatura associada à teoria do capital humano, perfil do profissional contábil, remuneração e estudos anteriores, foi proposto e estimado um modelo de regressão no intuito de analisar os fatores determinantes dos salários de contadores para a amostra em questão. Os resultados encontrados evidenciaram, em ordem de maior influência, que os fatores associados ao tamanho da empresa, nível de escolaridade, sexo, idade dos profissionais e tempo de empresa influenciam positivamente nos salários dos contadores. Esses resultados verificados corroboraram os achados encontrados nos estudos anteriores.

Palavras-chave: Contabilidade. Contador. Perfil do profissional contábil. Remuneração. Teoria do capital humano.

\begin{abstract}
The purpose of this research was to analyze through an econometric approach the determinant factors of accountants' financial remuneration of the municipalities of Cascavel, Foz do Iguaçu and Toledo in the year 2015. For the development of the research was used the archival data collected on the basis of the Annual Social Information Report. For the organization and analysis of the data, the quantitative methodological procedures were used. In addition, based on the literature associated with human capital theory, accounting professional profile, remuneration and previous studies, a regression model was proposed and estimated in order to analyze the determinant factors of accountants' financial remuneration for the sample in question. The results showed that, in order of greater influence, the factors associated with company size, education level, gender, age of professionals, and company time positively influence the salaries of accountants. These results corroborate with findings found in previous studies.
\end{abstract}

Keywords: Accounting. Accountant. Profile of the accounting professional. Remuneration. Human capital theory.

\footnotetext{
${ }^{1}$ Mestrado em Contabilidade pela Universidade Estadual do Oeste do Paraná (Unioeste), Cascavel, Paraná, Brasil. E-mail: samuellynconleandro@gmail.com

${ }^{2}$ Mestrado em Contabilidade pela Universidade Estadual do Oeste do Paraná, Cascavel, Paraná, Brasil. Contador da Universidade Federal do Paraná (UFPR), Curitiba, Paraná, Brasil.

${ }^{3}$ Doutorado em Economia Aplicada pela Universidade de São Paulo (ESALQ-USP), São Paulo, São Paulo, Brasil. Professora Associada Nível C da Universidade Estadual do Oeste do Paraná, Cascavel, Paraná, Brasil.
} 


\section{Introdução}

O mercado de trabalho passou por diversas mudanças ao longo do tempo, e nesse sentido cada vez mais são exigidas novas competências relacionadas a aspectos econômico, sociais, cultural e tecnológico dos profissionais da contabilidade (MARIN; LIMA; CASA NOVA, 2014). Diante disso, as mudanças nas práticas contábeis, logo, na atuação dos contadores evidenciam a necessidade da Contabilidade evoluir em conjunto com a sociedade, colocando assim o contador em uma posição significativa dentro das organizações (DE LA VIELLE; BIANCHI, 2016).

Essa necessidade de capacitação continuada tornou-se evidente com o advento da tecnologia da informação, cuja adoção pelas organizações tem sido cada vez maior, dado a necessidade de otimizar os processos operacionais e redução de custos. Nesse contexto, emerge a figura do contador, responsável por operacionalizar esses sistemas, visando sempre à geração de informações confiáveis, claras e concisas (COSTA, 2004).

Esse processo sistemático de mudança é uma realidade efetiva desde a formação do profissional contábil, antes pautada nos métodos tradicionais, e já se discute uma formação sobre a concepção construtivista, visando formar indivíduos ativos, com capacidade de pensar com criticidade, solucionar problemas, desenvolver habilidades interpessoais e de pesquisa (SILVA; GRÄBNER; BANDEIRA, 2004).

No que se refere à divisão social do trabalho, Alves et al. (2007) destacam as mudanças ocorridas a partir de século XX que trouxeram um impacto significativo na regionalização da divisão social do trabalho, do processo de acumulação capitalista, da reprodução da força de trabalho e dos processos políticos e ideológicos. Para esses autores, a Região Oeste paranaense é um exemplo dessas transformações, ocasionadas, sobretudo pelo aumento populacional de $51,18 \%$ ocorrido de 1970 a 2000.

Embora o total da população da Região Oeste do Paraná tenha aumentado expressivamente no período de 1970 a 2000, isso ocorreu de forma diferenciada entre seus municípios. Dessa forma, os autores Alves et al. (2007) analisando esse aumento, identificaram que os únicos municípios que mantiveram concentração populacional foram os polos regionais, ou seja, Cascavel, Foz do Iguaçu e Toledo. No final do ano de 2000, esses três municípios concentravam juntos $52,88 \%$ da população total da região, enquanto o restante da população estava distribuído entre os outros 47 municípios.

Neste sentido, destaca-se a importância desses três municípios para a Região Oeste paranaense, uma vez que Rippel (2005) afirma que o desenvolvimento de uma região está fortemente vinculado à dinâmica populacional e à organização do capital, uma vez que acabam transformando as condições "ambientais locais", moldando-as segundo seu interesse.

Considerando o campo universitário, destaca-se que são cinco instituições de ensino superior (IES) em Cascavel, cinco em Foz do Iguaçu e três em Toledo, totalizando treze IES que oferecem, atualmente, $10 \%$ do total das vagas ofertadas para os cursos presenciais de Ciências Contábeis no estado do Paraná. Os cursos à distância não foram levados em consideração em virtude da dificuldade de identificação do polo educacional em que se encontram as vagas.

Estudos anteriores voltaram-se para verificar os fatores determinantes da remuneração do profissional da contabilidade, em diferentes contextos, encontrando fatores como a formação continuada, o trabalho em conjunto com a graduação (MARTINS et al., 2012) e o gênero (BRENNAN; NOLAN; 1998; MARTINS et al., 2012; STEDHAM; YAMAMURA; SATOH, 2006).

Além disso, foi encontrado dentre os principais determinantes do salário do contador, o nível de escolaridade (ELFERNAN et al., 2009; GONZÁLEZ PACHECO; RUBIO SALINAS, 2009; MACHADO et al., 2014; MARTINS et al., 2012; MARTINS; MONTE, 2010; SANTANA JUNIOR; CALLADO, 2016), tempo de experiência e atuação no mercado (MARTINS; MONTE, 2010) 
e o tamanho da empresa (BRENNAN; NOLAN, 1998; MARTINS et al., 2012).

Diante disso, a questão dessa pesquisa consiste em: "quais os fatores determinantes do salário dos contadores?". Para responder essa questão, a pesquisa tem como objetivo analisar por meio de uma abordagem econométrica os fatores determinantes dos salários de contadores dos municípios de Cascavel, Foz do Iguaçu e Toledo no ano de 2015, considerando a importância desses municípios para a Região Oeste do Estado, além de receberem por ano em torno de 1422 novos estudantes, conforme dados do e-MEC (BRASIL, 2017).

Esta pesquisa é organizada em cinco seções. $\mathrm{Na}$ primeira seção é apresentada a introdução. A segunda seção retrata a revisão da literatura, e posteriormente, na terceira seção são detalhados os procedimentos metodológicos empregados na pesquisa. Já na quarta seção são apresentadas as análises e discussões dos resultados. Por fim, na quinta seção são destacadas as considerações finais.

\section{Referencial Teórico}

Nessa seção é apresentada a revisão da literatura utilizada para embasamento da pesquisa. Dessa forma, serão abordados os aspectos relacionados ao perfil do profissional contábil, remuneração e estudos anteriores.

\section{Teoria do capital humano}

A teoria do capital humano propõe que a obtenção de novos conhecimentos e habilidades maximizará o valor do capital humano dos indivíduos, e consequentemente sua empregabilidade, produtividade e remuneração (CUNHA, 2007). Diante disso, o investimento em educação sob a ótica da teoria do capital humano, segundo Cunha (2007), proporcionará aos indivíduos, além de melhores rendimentos futuros, uma destacada posição social. Esse investimento de acordo com Cunha (2007) não é de fácil mensuração, pois além dos custos diretos, isto é, os mais objetivos, possuem os custos indiretos, associados ao tempo dispendido com essas atividades.

Dessa forma, a teoria do capital humano segundo Cunha (2007) ganhou destaque com o trabalho de Becker (1962). Em seu trabalho, Becker (1962) propôs que, embora a aquisição de informações não tenha um efeito proporcional sobre a relação dos custos e ganhos, na medida em que é percebida aumentam as perspectivas de renda dos indivíduos. Além disso, essa questão em torno do investimento em capital humano, na perspectiva de Becker (1962), contribui para o entendimento da sistemática dos recursos intangíveis.

Em uma análise empírica, Becker (1962) apontou que o investimento em capital humano proporciona um efeito direto para os indivíduos mais experientes, uma vez que o retorno é adicionado aos ganhos. Já nos indivíduos menos experientes o investimento em capital humano reduz os ganhos, pois os custos são deduzidos dos ganhos. Entretanto, considerando o investimento em educação, determinados indivíduos podem receber uma remuneração melhor por terem adotado essa postura (BECKER, 1962).

Destarte, Cunha (2007) pontua que é definido como pressuposto da teoria do capital humano a inquietação dos indivíduos em investir na educação, e que os efeitos de adquirirem novas informações são a melhoria nas habilidades e conhecimentos. Nesse sentido, espera-se que essas competências melhorem a remuneração dos indivíduos, consequentemente a qualidade de vida e bem-estar social. Com isso, na próxima seção são discutidos os aspectos relacionados ao perfil do profissional contábil.

\section{Perfil do profissional contábil}

O perfil do profissional contábil vem sofrendo mudanças nos últimos tempos (MARIN; LIMA; CASA NOVA, 2014). O contador moderno é um homem de valor, consciente de que, em busca por uma maior remuneração, necessita acumular conhecimentos. Nessa mesma linha, Mohamed 
e Lashine (2003) afirmam que as necessidades do contabilista vêm se alterando, levando-o a expandir suas habilidades relacionadas tanto ao ambiente econômico, quanto ao político e social, ao invés de se limitar apenas ao conhecimento técnico.

Essas alterações na atuação do profissional contábil, decorrentes, dentre outros fatores, da globalização e das inovações em tecnologia da informação, levaram os profissionais a buscarem formas de desenvolverem suas competências e de adquirirem novas habilidades e conhecimentos (MOHAMED; LASHINE, 2003).

Ciente dessas mudanças e das novas exigências para o profissional contábil, a International Federation of Accountants (IFAC) publicou a IES 3, uma norma que prescreve a combinação de habilidades que os profissionais da área da contabilidade necessitam para atuarem de forma qualificada. Vigente desde 1 de julho de 2015, a IES 3 cita cinco habilidades, conforme descritas no Quadro 1.

Quadro 1 - As habilidades do profissional contábil.

\begin{tabular}{|c|c|}
\hline $\begin{array}{l}\text { Habilidades } \\
\text { intelectuais }\end{array}$ & $\begin{array}{l}\text { - Avaliar informações de uma variedade de fontes e perspectivas por meio de pesquisa, } \\
\text { análise e integração; } \\
\text { - Aplicar julgamento profissional, incluindo identificação e avaliação de alternativas, para } \\
\text { chegar a conclusões bem fundamentadas com base em todos os fatos e circunstâncias } \\
\text { relevantes; } \\
\text { - Identificar quando é apropriado consultar especialistas para resolver problemas e chegar a } \\
\text { conclusões; } \\
\text { - Aplicar raciocínio, análise crítica e pensamento inovador para resolver problemas; } \\
\text { - Recomendar soluções para problemas não estruturados e multifacetados. }\end{array}$ \\
\hline $\begin{array}{c}\text { Habilidades } \\
\text { interpessoais e } \\
\text { de comunicação }\end{array}$ & $\begin{array}{l}\text { - Mostrar cooperação e trabalho em equipe ao trabalhar para metas organizacionais; } \\
\text { - Comunicar de forma clara e concisa ao apresentar, discutir e relatar situações formais e } \\
\text { informais, tanto por escrito como oralmente; } \\
\text { - Demonstrar consciência com diferenças culturais e linguísticas em todas as comunicações; } \\
\text { - Escutar ativamente e aplicar técnicas de entrevista eficazes; } \\
\text { - Aplicar habilidades de negociação para alcançar soluções e acordos; } \\
\text { - Aplicar habilidades de consultoria para minimizar ou resolver conflitos, solucionar } \\
\text { - } \text { Aproblemas e maximizar oportunidades; }\end{array}$ \\
\hline $\begin{array}{c}\text { Habilidades } \\
\text { pessoais }\end{array}$ & $\begin{array}{l}\text { - Demonstrar compromisso com a aprendizagem ao longo da vida; } \\
\text { - Aplicar o ceticismo profissional questionando e avaliando criticamente todas as informações. } \\
\text { - Estabelecer altos padrões pessoais de entrega e monitorar o desempenho pessoal, através do } \\
\text { feedback de outros e da reflexão; } \\
\text { - Gerenciar tempo e recursos para alcançar compromissos profissionais; } \\
\text { - Antecipar desafios e planejar soluções possíveis; } \\
\text { - Pautar por uma mente aberta a novas oportunidades. }\end{array}$ \\
\hline $\begin{array}{c}\text { Habilidades } \\
\text { organizacionais }\end{array}$ & $\begin{array}{l}\text { - Realizar trabalhos de acordo com as práticas estabelecidas para cumprir os prazos prescritos; } \\
\text { - Analisar o próprio trabalho e o de outros para determinar se está em conformidade com os } \\
\text { padrões de qualidade da organização; } \\
\text { - Aplicar habilidades de gerenciamento de pessoas para motivar e desenvolver outras pessoas; } \\
\text { - Aplicar habilidades de delegação para entregar tarefas; } \\
\text { - Aplicar habilidades de liderança para influenciar outras pessoas a trabalharem em direção } \\
\text { aos objetivos organizacionais; } \\
\text { - Aplicar ferramentas e tecnologia apropriadas para aumentar a eficiência, a eficácia e } \\
\text { melhorar a tomada de decisões. }\end{array}$ \\
\hline
\end{tabular}

Fonte: Adaptado de International Federation of Accountants (2014) 
As habilidades intelectuais contribuem na identificação e solução de problemas, na análise crítica e na tomada de decisões. As técnicas e funcionais compreendem as habilidades específicas e gerais de contabilidade, já as habilidades pessoais são inerentes às atitudes e comportamentos do profissional contábil (SILVA; GRÄBNER; BANDEIRA, 2004).

Já as habilidades interpessoais e de comunicação são as que regem a interação do contador com outras áreas de conhecimento. E por sua vez, as habilidades organizacionais e de gerenciamento de negócios estão relacionadas ao funcionamento da organização (SILVA; GRÄBNER; BANDEIRA, 2004).

McMullen e Sanchez (2010) realizaram uma pesquisa nos Estados Unidos buscando identificar os requisitos importantes para a profissão contábil, bem como as habilidades necessárias para os contadores forenses americanos. Após a coleta de dados, concluíram que, dentre os conhecimentos necessários, destacaram-se a contabilidade básica, resolução de problemas, análise de dados, técnicas de entrevista e informática.

Com isso, em relação às características mais importantes estavam persistência, raciocínio estratégico e bom relacionamento interpessoal. Esta pesquisa serve para corroborar a ideia de que atualmente conhecimentos técnicos não bastam ao profissional da contabilidade; o mercado exige cada vez mais que este desenvolva novas habilidades e competências (MCMULLEN; SANCHEZ, 2010).

Assim, neste novo contexto de atuação do contador, é necessário que ele se sinta motivado a desenvolver habilidades, se especializar e adquirir os conhecimentos exigidos pelo mercado. Destacase diante disso, que a palavra motivação indica o processo pelo qual um conjunto de interesses e motivos explica, induz, incentiva, estimula ou provoca algum tipo de ação ou comportamento humano (MAXIMIANO, 2000).

Neste mesmo sentido, Robbins (2005) afirma que a motivação é o fator responsável pela intensidade, direção e persistência que o indivíduo possui para alcançar uma determinada meta ou objetivo. A seguir, na próxima seção, é discutido sobre os aspectos relacionados à remuneração.

\section{Remuneração}

A remuneração é um dos mais importantes e complexos sistemas de gerenciamento de recursos humanos (KRAUTER, 2009). Para Gómez-Mejía e Welbourne (1988) o sistema de remuneração é o repertório de opções de pagamentos disponíveis à gerência que pode, em algumas condições, ter um impacto no desempenho da organização e no uso efetivo de seus recursos humanos.

A remuneração pode ser financeira e não financeira. A remuneração financeira é a contrapartida econômica pelo trabalho, que na forma direta é representada pelo salário fixo (promove a equidade) e pelo salário variável (incentivos de desempenho) e na forma indireta, pelos benefícios (segurança e conforto); já a não financeira está relacionada ao desenvolvimento profissional e pessoal (HIPÓLITO; DUTRA, 2012; KRAUTER, 2009).

Figura 1 - Conceito de remuneração.

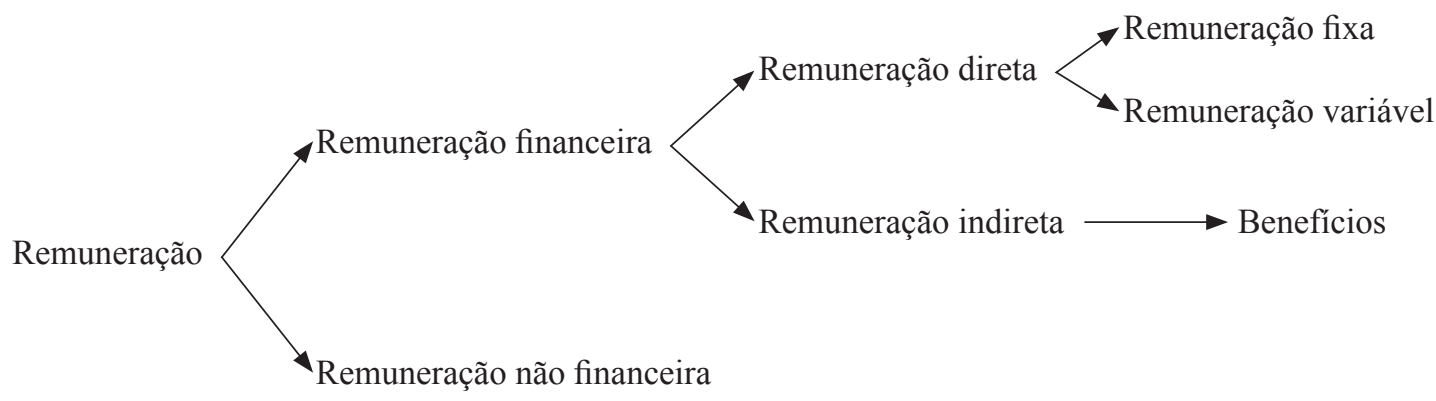

Fonte: Krauter (2009) 
É importante salientar que a remuneração precisa promover um sentimento de segurança, e a definição do padrão de vida dos indivíduos e seus dependentes, além de ser caracterizada como uma fonte de reconhecimento da atuação profissional dentro da organização. Diante disso, verifica-se a importância das organizações estabelecerem objetivos que direcionem os funcionários a atingi-los, pois dessa forma terão a percepção de que conforme o esforço demandando poderão maximizar seus benefícios (FAVARIM, 2011).

Com isso, no mercado de trabalho, os indivíduos buscam exercer alguma atividade em troca de uma contraprestação, uma vez que o indivíduo vende seu trabalho para outro indivíduo em troca de uma remuneração financeira ou benefícios. Nesse contexto, o trabalhador utilizará essa remuneração para satisfação das suas necessidades básicas (FAVARIM, 2011). Assim, na próxima seção são apresentados os estudos desenvolvidos sobre os aspectos relacionados à remuneração dos profissionais da contabilidade.

\section{Estudos anteriores}

No intuito de analisar quais os fatores que influenciam positivamente os salários dos contadores dos estados da Paraíba e do Rio Grande do Norte, os autores Martins et al. (2012) realizaram a aplicação de questionários para verificar qual a relação existente entre as variáveis analisadas e os níveis salariais dos profissionais contábeis. Os achados dessa pesquisa evidenciaram que os fatores com maior influência no salário dos contadores são aperfeiçoamento, trabalho realizado em conjunto com a graduação, o gênero do profissional, o tempo de formação e o tipo da empresa (MARTINS et al., 2012).

Nessa perspectiva, Machado et al. (2014) buscaram identificar o nível de influência do rendimento escolar, e de variáveis socioeconômicas no desempenho financeiro dos egressos do curso de Contabilidade de uma instituição de ensino superior no estado de Goiás. Os achados obtidos por meio da modelagem econométrica empregada na pesquisa evidenciaram que a experiência do egresso foi à única variável explicativa significante. Ainda, os resultados da pesquisa demonstraram que as diferenças nas remunerações dos egressos de Contabilidade estão associadas ao nível de conhecimento acumulado (MACHADO et al., 2014).

Já os autores Martins e Monte (2010) analisaram os fatores determinantes da variação salarial dos mestres em Ciências Contábeis titulados pelo Programa Multi-institucional e Inter-regional de Pós-graduação em Ciências Contábeis da UNB/ UFPB/UFPE/UFRN. Os achados evidenciaram que os principais fatores determinantes das variações salariais foram o fato de possuir graduação em Contabilidade, ter especialização, concluir a graduação com menor idade, tempo de experiência e ter como atividade principal a atuação no mercado (MARTINS; MONTE, 2010).

Além disso, Santana Junior e Callado (2016) buscaram analisar os fatores determinantes da remuneração dos contadores da Região Nordeste brasileira. Perfez a amostra do estudo o total de 14.855 observações de profissionais de contabilidade da Região Nordeste brasileira, retiradas da RAIS referente ao ano de 2014.

Os resultados evidenciaram que os profissionais com nível de mestrado são melhores remunerados que aqueles que possuem apenas o nível de graduação. Os achados também demonstraram que as empresas tributadas com base no simples nacional pagam salários menores, em relação às empresas que não estão sujeitas a esse regime de tributação (SANTANA JUNIOR; CALLADO, 2016).

Em nível internacional, os autores Elfernan et al. (2009) desenvolveram um estudo no Chile com o propósito de mensurar a influência do nível educacional no salário de profissionais de diversas áreas de atuação, inclusive dos contadores. Os achados evidenciaram que quanto maior o tempo de estudos, mais elevado o salário (ELFERNAN et al., 2009).

Ainda no contexto chileno, González Pacheco e Rubio Salinas (2009) verificaram a estimativa de 
retorno sobre a formação de profissionais de duas áreas distintas, dentre elas a contabilidade. Assim, os achados evidenciaram em ambos os casos uma recompensa significativa maior para os níveis de escolaridade (GONZÁLEZ PACHECO; RUBIO SALINAS, 2009).

Em um contexto profissional irlandês, os autores Brennan e Nolan (1998) analisaram a remuneração dos contadores irlandeses, buscando verificar possíveis diferenças salariais, bem como a causa dessa possível disparidade salarial entre os gêneros, em uma amostra composta por 1387 contadores, subdividida em 277 mulheres e 1110 homens (BRENNAN; NOLAN; 1998).

Nesse sentido, os achados do estudo evidenciaram uma relevante disparidade salarial entre o gênero dos profissionais; além disso, os resultados demonstraram que as variáveis associadas ao nível de responsabilidade, ao tamanho do empregador e os anos de experiência profissional foram as principais determinantes do salário de ambos profissionais (BRENNAN; NOLAN, 1998).

Com o mesmo objetivo, os autores Yamamura e Satoh (2006) buscaram identificar possíveis diferenças salariais entre o gênero dos contadores japoneses. A amostra da pesquisa foi constituída por meio de dados obtidos de 235 profissionais contabilistas no Japão, das cinco maiores empresas de contabilidade pública em Tóquio, Nagoya e Osaka em 2002 (STEDHAM; YAMAMURA; SATOH, 2006).

Os resultados do estudo apresentaram que o reconhecimento da discriminação baseada em gênero não é comum no Japão. Com isso, explorando a questão da satisfação, verificou-se que as mulheres não estavam menos satisfeitas com o salário que os homens (STEDHAM; YAMAMURA; SATOH, 2006). Diante desses achados encontrados na literatura, foram propostas cinco hipóteses:

H1: O nível de escolaridade influencia positivamente o salário do profissional contábil.

H2: O tamanho da empresa influencia positivamente o salário do profissional contábil.
H3: O tempo de empresa influencia positivamente o salário do profissional contábil.

H4: O gênero masculino influencia positivamente o salário do profissional contábil.

H5: A idade do profissional influencia positivamente o salário do profissional contábil.

\section{Metodologia}

Esse estudo consiste em uma pesquisa documental (FLICK, 2013), na medida em que os dados são extraídos de fonte pública, a RAIS, caracterizados como dados secundários (HAIR JUNIOR et al., 2005). Nesse sentido, os dados coletados se referem a informações profissionais sobre os contadores (CBO 252210) das cidades de Cascavel, Foz do Iguaçu e Toledo, no estado do Paraná.

A seleção dessas cidades deu-se por serem as mais populosas e economicamente representativas da Região Oeste do Paraná, a qual possui uma notável participação na geração de empregos e riqueza para o estado. Destaca-se, que a Região Oeste do Paraná é fortemente estimulada pelos setores relacionados às atividades do agronegócio (FERREIRA et al., 2017; GOMES et al., 2018).

Além disso, a pesquisa é caracterizada como quantitativa, dado os procedimentos metodológicos e o empregado da abordagem multivariada para análises dos resultados (HAIR JUNIOR et al., 2005; RICHARDSON, 1999). Assim, para organização dos dados será utilizado o software Microsoft Excel e para análise dos dados o software EViews. Nessa perspectiva, na Equação 1 é apresentada a modelagem econométrica utilizada na pesquisa.

$$
\begin{gathered}
\log \left(\frac{\text { Rem }_{i}}{\text { Hora }_{i}}\right)=\varphi_{0}+\varphi_{1} \operatorname{Esc}_{i}+\varphi_{2} \operatorname{Tam}_{i} \\
+\varphi_{3} \operatorname{Tem}_{i}+\varphi_{4} \operatorname{Sex}_{i}+\varphi_{5} \operatorname{Ida}_{i}+\varepsilon_{i}
\end{gathered}
$$

Onde:

Rem $=$ Remuneração financeira do contador. Hora $=$ Quantidade de horas trabalhadas pelo contador.

$E s c=$ Nível de escolaridade do contador. 
Tam $=$ Tamanho da empresa do contador.

Tem $=$ Tempo de empresa do contador.

Sex $=$ Sexo do contador.

$I d a=$ Idade do contador.

$\varepsilon_{i}=$ Erro.

Diante disso, o modelo econométrico proposto na pesquisa se trata de um modelo de regressão múltipla, na medida em que há mais de uma variável explanatória. Cabe ressaltar que a respectiva modelagem permite aos pesquisadores realizarem a inferência estatística, isto é, testar hipóteses (GUJARATI; PORTER, 2011). No Quadro 2 é detalhada a construção das variáveis analisadas na pesquisa.

Quadro 2 - Delineamento metodológico das variáveis.

\begin{tabular}{|l|l|c|l|}
\hline \multicolumn{1}{|c|}{ Fator } & \multicolumn{1}{|c|}{ Descrição dos fatores } & Variáveis & \multicolumn{1}{c|}{ Valor } \\
\hline $\begin{array}{l}\text { Remuneração } \\
\text { financeira }\end{array}$ & $\begin{array}{l}\text { Remuneração financeira especificada } \\
\text { no contrato (CLT) / horas de trabalho. }\end{array}$ & $\log \left(\frac{\text { Rem }_{i}}{\mathrm{Hora}_{i}}\right)$ & Quantitativa contínua. \\
\hline Escolaridade & $\begin{array}{l}\text { Classificados a partir do ensino } \\
\text { superior completo. }\end{array}$ & $\begin{array}{l}\text { Dummy: 1 - Caso o indivíduo tenha um nível } \\
\text { de escolaridade a partir do ensino superior } \\
\text { completo; 0 - Caso contrário. }\end{array}$ \\
\hline $\begin{array}{l}\text { Tamanho } \\
\text { da empresa }\end{array}$ & $\begin{array}{l}\text { Classificadas pela RAIS acima de 5 } \\
\text { (acima de 50 empregados ativos). }\end{array}$ & $\operatorname{Tam}_{i}$ & $\begin{array}{l}\text { Dummy: 1 - Caso a empresa seja classificada } \\
\text { pelas RAIS acima de 5; 0 - Caso contrário. }\end{array}$ \\
\hline $\begin{array}{l}\text { Tempo } \\
\text { da empresa }\end{array}$ & $\begin{array}{l}\text { Tempo de trabalho do colaborador } \\
\text { em meses. }\end{array}$ & $\operatorname{Tem}_{i}$ & Quantitativa contínua. \\
\hline Sexo & Masculino / Feminino. & $\begin{array}{l}\text { Dummy: 1 - Caso o indivíduo seja do sexo } \\
\text { masculino; 0 - Caso contrário. }\end{array}$ \\
\hline Idade & Idade do colaborador. & Quantitativa contínua. \\
\hline
\end{tabular}

Fonte: Autores

Após a coleta de dados para as variáveis apresentadas no Quadro 2, a amostra da pesquisa foi constituída por 682 observações referentes ao salário dos contadores das cidades em questão. Entretanto, foram realizadas exclusões de quatro observações com valores zerados e cinco observações com informações relativas à remuneração financeira dos contadores, abaixo do salário mínimo vigente em 2015, para a carga horária de 44 horas semanais, totalizando assim 673 observações analisadas.

Com isso, no intuito de apresentar as hipóteses propostas e as respectivas influências esperadas das variáveis explicativas na variável dependente, segue a Figura 2 sobre o constructo da pesquisa.

Figura 2 - Constructo da pesquisa.

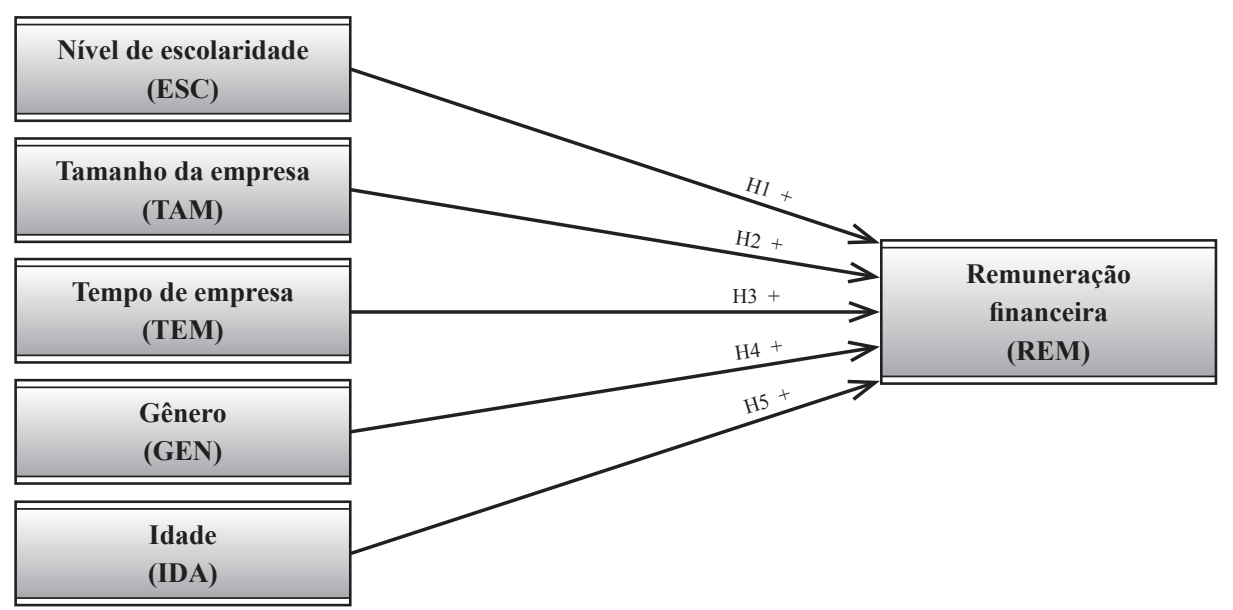

Fonte: Autores 
É possível observar na Figura 2 as variáveis da pesquisa, bem como as hipóteses construídas com base na literatura disponível para a estimação por meio da modelagem econométrica disposta na Equação 1. Diante disso, na próxima seção são apresentados e discutidos os principais achados.

\section{Análise dos Resultados}

Nessa seção são apresentados a estatística descritiva dos dados e os resultados encontrados com o modelo proposto na pesquisa.

\section{Análise descritiva dos dados}

Na Tabela 1 é apresentada a estatística descritiva das observações coletadas para a construção das variáveis selecionadas, no intuito de estimar o modelo de regressão proposto na pesquisa.

Tabela 1 - Estatística descritiva dos dados.

Painel A - Remuneração dos contadores

Remuneração / horas trabalhadas

$$
\begin{aligned}
& \text { (R\$) Média } \\
& \text { (R\$) Máximo } \\
& \text { (R\$) Mínimo } \\
& \text { (=) Observações } \\
& \text { (\%) Observações }
\end{aligned}
$$

$\begin{array}{rrrr}\text { Cascavel } & \text { Foz do Iguaçu } & \text { Toledo } & \text { Total } \\ 79,13 & 110,83 & 97,33 & 90,93 \\ 467,55 & 644,76 & 703,79 & 703,79 \\ 21,68 & 22,73 & 27,16 & 21,68 \\ 366 & 174 & 133 & 673 \\ 54 & 26 & 20 & 100\end{array}$

263

103

109

495

Classificados abaixo do ensino superior completo

\section{Painel C - Tamanho da empresa}

Classificadas pela RAIS acima de 5 (acima de 50 empregados ativos)

142

Classificadas pela RAIS abaixo de 5 (acima de 50 empregados ativos)

Painel D - Tempo de empresa

Média

Máximo

Mínimo

Painel E - Sexo do contador

(=) Masculino

158

(\%) Masculino

(=) Feminino

(\%) Feminino

$\begin{array}{rrrr}64 & 67 & 55 & 63 \\ 450 & 403 & 352 & 450 \\ 0 & 0 & 1 & 0\end{array}$

$\begin{array}{lll}51 & 24 & 178\end{array}$

Painel F - Idade do contador

Média

Máximo

Mínimo

\section{5}

99

64

69

281

24

3

57

18

$\begin{array}{rrr}89 & 71 & 318 \\ 51 & 53 & 47 \\ 85 & 62 & 355 \\ 49 & 47 & 53\end{array}$

Fonte: Dados da pesquisa (2017) 
Analisando os dados trabalhados na pesquisa sobre uma abordagem estatística descritiva, foi possível verificar que das 673 observações contempladas na amostra, aproximadamente 54\% são referentes ao município de Cascavel, 26\% de Foz do Iguaçu e 20\% de Toledo. Dessa forma, verificou-se que o município de Cascavel é o que mais empregou contadores, uma quantidade de 366 profissionais registrados na base de dados da RAIS.

Já com relação ao salário médio por horas trabalhadas dos municípios em questão, em Cascavel foi $\mathrm{R} \$ 79,13$, em Foz do Iguaçu R\$ 110,83, e em Toledo R\$ 97,33. Assim, considerando a média salarial por horas trabalhadas dos profissionais contadores, o município de Foz do Iguaçu é o que melhor remunera esses profissionais, aproximadamente $13,87 \%$ superior ao município de Toledo e $40 \%$ ao de Cascavel. Entretanto, o maior valor salarial por horas trabalhadas foi de $\mathrm{R} \$ 703,79$ no município de Toledo, e o menor valor foi de $\mathrm{R} \$ 21,68$ no município de Cascavel.

Com relação ao sexo dos profissionais, observou-se que $53 \%$ são do sexo feminino, enquanto $47 \%$ são do masculino. Esse resultado representa uma participação maior de profissionais do sexo feminino atuando na área contábil nesses três municípios analisados. Ainda, analisando a média de idade dos profissionais contábeis, foi em torno de 36 anos. Entretanto, para a profissional contábil do sexo feminino a média de idade foi de 34 anos, enquanto para o profissional do sexo masculino foi de 38 anos. O profissional contábil mais velho possui 71 anos de idade.

Além disso, o tempo médio de empresa dos profissionais da área contábil foi de aproximadamente 63 meses. Cabe ressaltar que o profissional com maior tempo de empresa possui em torno de 38 anos de exercício. E com relação ao nível de escolaridade, observou-se que aproximadamente $74 \%$ dos profissionais possuem o nível de escolaridade a partir do ensino superior completo. Com isso, na próxima seção são apresentados os achados sobre a estimação do modelo de regressão proposto na pesquisa.

\section{Influência sobre a remuneração \\ financeira dos contadores}

Por identificar na pesquisa a presença de heterocedasticidade ( $\mathrm{p}$ valor $<0,01$ ), foi necessário, para corrigir este problema, estimar o modelo proposto pelo método de estimação de heterocedasticidade consistente de White (HILL; JUDGE; GRIFFITHS, 2010).

$\mathrm{Na}$ Tabela 2 são apresentados os resultados obtidos por meio da estimação do modelo de regressão proposto na pesquisa.

Tabela 2 - Resultados da estimação do modelo de regressão.

\begin{tabular}{ccccc}
\hline Variáveis & Coeficientes & Erro padrão & Estatística t & P valor \\
\hline C & 3,331988 & 0,069514 & 47,93261 & $0,00^{* * *}$ \\
ESC & 0,313422 & 0,041998 & 7,462757 & $0,00^{* * *}$ \\
TAM & 0,367968 & 0,037645 & 9,774711 & $0,00^{* * *}$ \\
TEM & 0,002735 & 0,000297 & 9,218072 & $0,00^{* * *}$ \\
SEX & 0,120115 & 0,036767 & 3,266953 & $0,00^{* * *}$ \\
IDA & 0,009799 & 0,002108 & 4,648360 & $0,00^{* * *}$ \\
R-squared & 0,430934 & & & \\
Prob (F-statistic) & $0,0000^{* * *}$ & & & \\
\hline
\end{tabular}

Fonte: Dados da pesquisa (2017)

$* * * 1 \%$ de significância. 
Observa-se de acordo com os resultados evidenciados na Tabela 2 que o r2 explica aproximadamente $43 \%$ das variações na variável dependente, isto é, no salário dos contadores. Diante disso, em torno de $57 \%$ das variações são explicadas por outras variáveis, fator que devido à heterogeneidade da amostra considera-se razoável. Ainda, constatou-se mediante o teste $\mathrm{f} o \mathrm{p}$ valor menor que $1 \%$, consequentemente se rejeita a hipótese nula de que os coeficientes analisados no modelo são estatisticamente iguais à zero.

Além disso, verificou-se que os coeficientes associados às variáveis analisadas por meio do modelo, tanto as variáveis explicativas como a constante foram estatisticamente significantes ao nível de $1 \%$ no teste t. Nesse sentido, a constante demonstrou que o valor do salário médio dos contadores considerando os municípios de Cascavel, Foz do Iguaçu e Toledo é anti-log (3.331988), dado por R \$ 2.147,77 em unidade monetária.

Dessa forma, o coeficiente associado ao nível de escolaridade apresentou uma elevação no salário dos contadores de aproximadamente $37 \%\left(\left(e^{0,313422}-1\right) \times 100\right)$. Esse achado referente ao nível de escolaridade dos contadores corrobora os estudos de Elfernan et al. (2009), González Pacheco e Rubio Salinas (2009), Machado et al. (2014), Martins et al. (2012), Martins e Monte (2010) e Santana Junior e Callado (2016).

Já o fator associado ao tamanho da empresa evidenciou uma elevação salarial em torno de $45 \%$ $\left(\left(e^{0,367968}-1\right) \times 100\right)$ no salário dos contadores. Observa-se pelos resultados apresentados, que o fator associado ao tamanho da empresa é o que mais influencia positivamente nos salários dos contadores. Essa influência positiva também foi verificada nos trabalhos de Brennan e Nolan (1998) e Martins et al. (2012).

Por conseguinte, o fator associado ao tempo de empresa demonstrou uma elevação de salário para os contadores de aproximadamente 0,3\% $\left(\left(e^{0,002735}-1\right) \times 100\right)$. Nota-se que essa influência positiva do tempo de empresa nos salários dos contadores corrobora o resultado encontrado no estudo de Martins e Monte (2010).
Em relação ao fator associado ao sexo do profissional contábil, destacou-se que eleva o salário do contador em torno de $13 \%\left(\left(e^{0,120115}-1\right)\right.$ $\mathrm{x}$ 100). Essa disparidade salarial estatisticamente significante no salário dos contadores, considerando o peso maior para o profissional do sexo masculino, é consoante aos achados de Brennan e Nolan (1998) e Martins et al. (2012).

E por fim, verificou-se que o fator associado à idade do profissional eleva aproximadamente $1 \%\left(\left(e^{0,009799}-1\right) \times 100\right)$ o salário dos contadores. Com isso, considerando os resultados encontrados e discutidos nessa seção, a seguir são apresentadas as considerações finais dessa pesquisa, ressaltando os principais achados relativos à amostra delimitada na pesquisa.

\section{Considerações Finais}

O objetivo dessa pesquisa foi analisar por meio de uma abordagem econométrica os fatores determinantes dos salários de contadores dos municípios de Cascavel, Foz do Iguaçu e Toledo no ano de 2015. Nessa perspectiva, verificou-se que os resultados encontrados diante da análise realizada por meio da modelagem econométrica proposta atingiram o respectivo objetivo proposto.

Destaca-se que o profissional contábil atua em um cenário em constante mudança, constituído por fatores que exigem do contador o constante aprimoramento profissional para melhor exercer a profissão (MARIN; LIMA; CASA NOVA, 2014). Além disso, observa-se que a contabilidade possui um papel fundamental para o desenvolvimento e sustentabilidade das organizações. Nesse sentido, a atuação do contador é considerada como um aspecto significativo para que a contabilidade possa atingir esse objetivo (DE LA VIELLE; BIANCHI, 2016).

Os resultados da pesquisa corroboraram os achados nos estudos anteriores, ressaltando que os fatores associados ao nível de escolaridade, tempo de empresa, tamanho da empresa, sexo e idade influenciam positivamente o salário dos contadores. Cabe ressaltar que os achados da 
pesquisa não podem ser generalizados, uma vez que o intuito foi analisar os fatores que influenciam o salário dos contadores, delimitando os municípios de Cascavel, Foz do Iguaçu e Toledo.

Sugere-se para estudos futuros a análise de outros municípios ou microrregiões, tendo em vista que abordagens encontradas nos estudos anteriores tratam a temática sobre uma abrangência maior. Além disso, sugere-se para novos estudos uma abordagem por natureza jurídica das empresas a serem analisadas, considerando a questão da organização estrutural público ou privado.

\section{Referências}

ALVES, L. R., LIMA, J. F.; RIPPEL, R.; PIACENTI, C. A. O continuum, a localização do emprego e a configuração espacial do Oeste do Paraná. Revista de História Econômica e Economia Regional Aplicada, Juiz de Fora, v. 2, n. 2, p. 2446, 2007.

BECKER, G. S. Investment in human capital: a theoretical analysis. Journal of Political Economy, Chicago, v. 70, n. 5, part. 2, p. 9-49, 1962.

BRENNAN, N.; NOLAN, P. Employment and remuneration of Irish chartered accountants: evidence of gender differences. European Accounting Review, London, v. 7, n. 2, p. 237-255, 1998.

COSTA,S.A.Opapeldocontadornaimplementação, desenvolvimento e estabilização de sistemas integrados de gestão: um estudo de caso de duas grandes empresas do DF. In: INTERNATIONAL CONFERENCE ON INFORMATION SYSTEMS AND TECHNOLOGY MANAGEMENT, 2004, São Paulo. Anais [...]. São Paulo: USP, 2004. p. $1-19$.

CUNHA, J. V. A. Doutores em ciências contábeis da FEA/USP: análise sob a óptica da teoria do capital humano. 2007. Tese (Doutorado em Controladoria e Contabilidade: Contabilidade) Faculdade de Economia, Administração e Contabilidade, Universidade de São Paulo, São Paulo, 2007.
DE LA VIELLE, A. P.; BIANCHI, M. Profissão contábil em guias de cursos de graduação: perfil do contador, rotinas profissionais e mercado de trabalho. Revista de Administração e Contabilidade: RAC, Santo Ângelo, v. 15, n. 29, 2016.

ELFERNAN, R.; RAMOS, J.; COBLE, D.; SOTO, C. Determinantes de los salarios por carrera. Santiago: Universidad de Chile, 2009.

BRASIL. Ministério da Educação. e-MEC. Cadastro Nacional de Cursos e Instituições de Educação Superior: cadastro e-MEC. Brasília: E-MEC, 2017. Disponível em: https://bit. ly/38vqpys. Acesso em: 11 nov. 2017.

FAVARIM, F. N. Remuneração e salário: uma abordagem jurídico/administrativa. Revista de Ciências Gerenciais, Valinhos, v. 15, n. 21, p. 209224, 2011.

FERREIRA, R. M.; LIMA, S. L. L.; GOMES, A. R. V.; BERTOLINI, G. R. F. Análise de Projetos e Investimentos: Principais Técnicas Utilizadas pelas Cooperativas Agroindustriais. Revista de Contabilidade do Mestrado em Ciências Contábeis da UERJ, Rio de Janeiro, v. 22, n. 1, p. 66-83, 2017.

FLICK, U. Introdução à metodologia científica: um guia para iniciantes. Tradução de Magda Lopes. Porto Alegre: Penso, 2013.

GOMES, A. R. V.; LIMA, S. L. L.; ARAÚJO, M. P.; JOHAM, J. A. O agronegócio é um bom negócio? Uma perspectiva sobre a remuneração financeira do administrador na região oeste do estado do Paraná. Perspectivas Contemporâneas, Campo Mourão, v. 13, n. 3, p. 15-33, 2018.

GÓMEZ-MEJIA, L. R.; WELBOURNE, T. M. Compensation strategy: an overview and future steps. Human Resource Planning, Toronto, v. 11, n. 3, p. 173-189, 1988.

GONZÁlEZ PACHECO, M. P.; RUBIO SALINAS, M. C. Variaciones del salario en función del área de trabajo para las carreras de ingeniería comercial y contador auditor: estudio de las variaciones del salario en las carreras de ingeniería comercial y contador auditor controlando por área de trabajo, puntajes de prueba de selección universitaria y condiciones socioeconómicas. Santiago: Universidad de Chile, 2009. 
GUJARATI, D. N.; PORTER, D. C. Econometria básica-5. Porto Alegre: AMGH Editora, 2011.

HAIR JUNIOR, J. F. BABIN, B.; MONEY, A.; SAMOUEL, P. Fundamentos de métodos de pesquisa em administração. Porto Alegre: Bookman Ed., 2005.

HILL, R. C.; JUDGE, G. G.; GRIFFITHS, W. E. Econometria. 3. ed. São Paulo: Saraiva, 2010.

HIPÓLITO, J. A. M.; DUTRA, J. S. Remuneração e recompensas. Rio de Janeiro: Elsevier, 2012.

INTERNATIONAL FEDERATION OF ACCOUNTANTS - IFAC. IES 3, initial professional development-professional skills (revised). New York: IFAC, 2014. Disponível em: https://bit.ly/38vOFRa. Acesso em: 3 out. 2017.

KRAUTER, E. Contribuições do sistema de remuneração dos executivos para o desempenho financeiro: um estudo com empresas industriais brasileiras. 2009. Tese (Doutorado em Administração) - Faculdade de Economia, Administração e Contabilidade da Universidade de São Paulo, São Paulo, 2009.

MACHADO, L. S.; MACHADO, M. R. R.; CARVALHO, C. R. R.; SOUZA, E. S. de. Variáveis que influenciam no desempenho financeiro dos egressos de contabilidade: um estudo em uma instituição de ensino superior do estado de goiás. ConTexto, Porto Alegre, v. 14, n. 28, p. 53-67, set./ dez. 2014.

MARIN, T. I. S.; LIMA, S. J.; CASA NOVA, S. P. Formação do contador: o que o mercado quer, é o que ele tem? Um estudo sobre o perfil profissional dos alunos de ciências contábeis da FEA-USP. Contabilidade Vista \& Revista, Belo Horizonte, v. 25, n. 2, p. 59-83, 2014.

MARTINS, O. S. et al. Fatores que influenciam os salários dos contadores à luz das teorias econômicas do emprego: um estudo exploratório na Paraíba e no Rio Grande do Norte. Revista Brasileira de Contabilidade, Brasília, n. 176, p. 72-85, 2012.

MARTINS, O. S.; MONTE, P. A. Fatores determinantes da variação salarial dos mestres em contabilidade. Pensar Contábil, Rio de Janeiro, v. 12, n. 49, p. 13-22, 2010.
MAXIMIANO, A. C. A. Introdução à administração. 5. ed. São Paulo: Atlas, 2000.

MCMULLEN, D. A.; SANCHEZ, M. H. A preliminary investigation of the necessary skills, education requirements, and training requirements for forensic accountants. Journal of Forensic \& Investigative Accounting, Salt Lake City, v. 2, n. 2, p. 30-48, 2010.

MOHAMED, E. K.; LASHINE, S. H. Accounting knowledge and skills and challenges of a global business environment. Managerial Finance, Melbourne, v. 29, n. 7, p. 3-16, p. 3-16, 2003.

RICHARDSON, M. Fundamentos da metodologia cientifica. São Paulo, 1999.

RIPPEL, R. Migração e desenvolvimento econômico no oeste do Estado do Paraná: uma análise de 1950 a 2000. 2005. 250 f. Tese (Doutorado em Demografia) - Universidade Estadual de Campinas, São Paulo, 2005.

ROBBINS, S.P. Comportamento organizacional. São Paulo: Pearson Prentice Hall, 2005.

SANTANA JUNIOR, G. M.; CALLADO, A. L. C. Fatores determinantes da remuneração dos contadores: um estudo exploratório no nordeste brasileiro. In: CONGRESSO DE ADMINISTRAÇÃO, SOCIEDADE E INOVAÇÃO - CASI, 7., 2016, Juiz de Fora. Anais [...]. Juiz de Fora: UFJF, 2016. Disponível em: https://bit.ly/2VTb5Xr. Acesso em: 3 out. 2017.

SILVA, T. M.; GRÄBNER, S.; BANDEIRA, A. M. Perspectiva atual para a formação do contador. Revista Eletrônica de Contabilidade, Santa Maria, v. 1, n. 1, set. 2004. Pdf. 31.

STEDHAM, Y.; YAMAMURA, J. H.; SATOH, M. Gender and salary: a study of accountants in Japan. Asia Pacific Journal of Human Resources, Melbourne, v. 44, n. 1, p. 46-66, 2006.

Recebido em: 19 fev. 2020 Aceito em: 27 abr. 2020 
